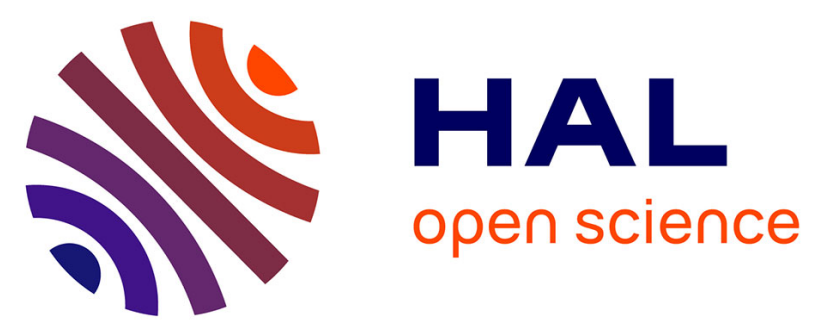

\title{
Spatial variability in carbon and nitrogen related traits in apple trees: the effects of the light environment and crop load
}

\author{
Jérome Ngao, Sébastien Martinez, André Marquier, Sylvie Bluy, Brigitte \\ Saint-Joanis, Evelyne Costes, Benoit Pallas
}

\section{To cite this version:}

Jérome Ngao, Sébastien Martinez, André Marquier, Sylvie Bluy, Brigitte Saint-Joanis, et al.. Spatial variability in carbon and nitrogen related traits in apple trees: the effects of the light environment and crop load. Journal of Experimental Botany, 2020, 72 (5), pp.1933-1945. 10.1093/jxb/eraa559 . hal-03049915

\section{HAL Id: hal-03049915 \\ https://hal.inrae.fr/hal-03049915}

Submitted on 10 Dec 2020

HAL is a multi-disciplinary open access archive for the deposit and dissemination of scientific research documents, whether they are published or not. The documents may come from teaching and research institutions in France or abroad, or from public or private research centers.
L'archive ouverte pluridisciplinaire HAL, est destinée au dépôt et à la diffusion de documents scientifiques de niveau recherche, publiés ou non, émanant des établissements d'enseignement et de recherche français ou étrangers, des laboratoires publics ou privés. 
Spatial variability in carbon and nitrogen related traits in apple trees: the effects of the light environment and crop load

Jérôme Ngao $^{1 *}$, Sébastien Martinez ${ }^{2,3}$, André Marquier ${ }^{1}$, Sylvie Bluy ${ }^{2}$, Brigitte SaintJoanis $^{1}$, Evelyne Costes ${ }^{2}$, Benoît Pallas ${ }^{2}$

${ }^{1}$ Université Clermont Auvergne, INRAE, PIAF, F-63000 Clermont-Ferrand, France

${ }^{2}$ Université de Montpellier, AGAP, INRAE, CIRAD, Institut Agro, F-34000 Montpellier, France

*for correspondence: jerome.ngao@inrae.fr

\section{HIGHLIGHTS}

Acclimation of leaf traits to light in apple trees depends on the fruit demand for carbon and is negligible when fruit loads are small 


\begin{abstract}
Photosynthetic carbon assimilation rates are highly dependent on environmental factors such as light availability and on metabolic limitations such as the demand for carbon by sink organs. The relative effects of light and sink demand on photosynthesis in perennial plants such as trees remain poorly characterised. The aim of the present study was therefore to characterize the relationships between light and fruit load on a range of leaf traits including photosynthesis, nonstructural carbohydrate $(N S C)$ contents, leaf structure and nitrogen-related variables in fruiting ('ON') and nonfruiting ('OFF') 'Golden Delicious' apple trees. We show that crop status (at the tree scale) exerts a greater influence over leaf traits than the local light environment, or the local fruit load. High rates of photosynthesis were observed in the ON trees. This was correlated with a high leaf nitrogen content. In contrast, little spatial variability in photosynthesis rates was observed in the OFF trees. The lack of variation in photosynthesis rates was associated with high leaf NSC contents at the tree level. Taken together, these results suggest that low carbon demand leads to feedback limitations on photosynthesis resulting in a low level of within-tree variability. These findings provide new insights into carbon and nitrogen allocations within trees that are heavily dependent on carbon demand.
\end{abstract}

Keywords: Light Harvesting, Leaf Photosynthesis, Light Microclimate, Nonstructural Carbon, Source-Sink Relationships, Spatial Variability 


\section{INTRODUCTION}

Within-plant microclimate gradients, such as those due to incoming light, air temperature, humidity, and wind, locally affect organ function and structure. Leaves respond to multiple constraints in various ways; these responses were gathered into a framework built over a large range of species, the so-called "leaf economics spectrum" (Wright et al., 2004; Niinements et al., 2015). Leaves acclimate to changing light throughout plant development. Light acclimation has been intensively studied for decades, as incoming light is one of most important resources for leaf net carbon $(C)$ assimilation $\left(A_{n e t}\right)$ and energy balance. In trees, numerous studies have reported decreasing $A_{\text {net }}$ from the upper to lower layers of forest ecosystems. The authors have linked these photosynthetic profiles to available light and traits involved in light harvesting and photosynthetic capacities, such as nitrogen $(\mathrm{N})$ content per unit area (Hollinger, 1996; Makela et al., 2008; Mc Murtrie and Dewar, 2011; Niinemets et al., 2004; Thornley, 2004). These relationships have led to "the optimization hypothesis". Following this hypothesis, the $\mathrm{C}$ and $\mathrm{N}$ economy is oriented towards investment of leaf $\mathrm{N}$ and leaf biomass for maximum light interception and C return on protein invested (Mooney, 1979; Bloom, 1985). This optimization has also been considered in models that account for within-tree $\mathrm{N}$ distribution and leaf gas exchanges that depend on incoming radiation at the individual scale (e.g., Le Roux et al., 2001, Prieto et al., 2012; Buckley et al., 2013) and in ecosystem models at a larger scale (Davi et al., 2005; Franklin, 2007). However, within that framework, both the leaf biochemical parameters driving variations in $A_{n e t}$ and stomatal conductance are assumed to respond to $\mathrm{N}$ allocation and abiotic factors only. Therefore, the influence of endogenous factors such as source:sink relationships on the acclimation of leaves to light gradients has been much less investigated, even if they appear to impact many $\mathrm{C}$ - or N-related processes at the plant scale (Quilot et al. 2004; Urban et al. 2004, Poirier-Pocovi et al. 2018).

The lack of optimal distribution of $A_{n e t}$ and its associated traits within trees has been noted in some studies, and nonoptimal distribution is explained by unidentified constraints that could involve source:sink relationships (Niinemets, 2012; Buckley et al., 2013; Hirosaka, 2014). There is a growing body of compelling evidence suggesting that, at the tree scale, leaf $\mathrm{C}$ function is strongly sink-driven. This phenomenon is usually observed through the downward regulation of $A_{\text {net }}$ when carbon demand is low (Sheen, 1994; Paul and Foyer, 2001; Quentin et al., 2013; Pallas et al. 2018). This decrease in $A_{\text {net }}$ is associated with a change in nonstructural carbohydrate (NSC, mostly starch and soluble sugars) turnover, 
which leads to a global increase in NSC in leaves when the C demand of reproductive organs is low or on girdled branches (Nebauer et al., 2011; Poirier-Pocovi et al., 2018; Urban et al. 2004; 2007). This adjustment of photosynthetic capacity to carbon demand and storage capacity can override the direct short-term control of photosynthesis by light and $\mathrm{CO}_{2}(\mathrm{Paul}$ and Foyer, 2001).

Fruit trees are of major interest for studying the impact of source-sink relationships on carbon metabolism because they are naturally prone to biennial bearing, which leads to contrasting intensities of competition for $\mathrm{C}$ between organs, which depends on the year (Monselise and Goldschmidt 1982). Moreover, in fruit trees, the local effect of fruit on the $A_{n e t}$ of nearby leaves has also been noted (e.g., Bairam et al., 2019; Gucci et al., 1995; Palmer et al., 1991; Saa and Brown, 2014; Syvertsen et al., 2003), even though a tree-scale effect of fruit presence has also been shown (Palmer et al., 1991; Walcroft et al., 2004; Pallas et al., 2018; Belhassine et al. 2019). It is thus still unclear at which spatial scale the downregulation of leaf $A_{n e t}$ by NSC contents is exerted: the tree scale (via the crop load of the whole tree) or at the local (shoot) scale (through local fruit).

Photosynthetic-associated variables also interact with crop load and $\mathrm{C}$ demand at different scales of tree organization (Gucci et al., 1995; Urban et al., 2004; Palmer et al., 1991; Saa and Brown, 2014). In that respect, leaf $\mathrm{N}$ increases with crop load (Urban et al., 2004; Stander et al., 2017), presumably because the amount of $\mathrm{N}$ absorbed by roots increases (Ding et al., 2017). In some cases, competition for $\mathrm{N}$ allocation between a growing shoot that bears fruit and a nearby vegetative shoot may decrease $A_{n e t}$ in the nearby leaves by reducing their $\mathrm{N}$ content (Saa and Brown, 2014 on almond trees). The light gradient within a single tree is another cause of major variation in leaf $\mathrm{N}$. The latter can be expressed through either the bulk $\mathrm{N}$ concentration (per dry mass basis, $\mathrm{Nm}$ ) or variations in leaf mass per area (LMA, if leaf $\mathrm{N}$ is expressed per unit area, $N a$ ), with $L M A$ being the ratio between the leaf dry weight $(L D W)$ and the leaf surface area $(L a)$. As $L M A$ is also positively correlated with light exposure (Poorter et al., 2019), it is thus considered the main driver for increasing $A_{\text {net }}$ among and within species (Niinemets, 1999). The influence of $L M A$ is considered greater than leaf $\mathrm{N}$ content and is related to seasonal changes in functional and structural $A_{n e t}$-related traits (Montpied et al., 2009). However, little is known about LMA variation as a function of crop load. LMA is reduced for fruiting orange trees compared with $50 \%$ defruited trees and for leaves of fruiting shoots compared with those of nonfruiting ones (Syvertsen et al., 2003). 
Conversely, Urban et al. (2004) did not observe a variation in LMA with crop load for mango trees.

This study aims to determine how the spatial variability resulting from local acclimation to intercepted light could be modulated by source-sink relationships. More precisely, we studied 'Golden Delicious' apple trees with either high or low crop loads. For these trees, we concomitantly assessed the impacts of intercepted light and crop load on within-tree spatial variability in (i) leaf photosynthesis, (ii) leaf structural traits (LMA, leaf weight), (iii) $\mathrm{N}$ related traits ( $\mathrm{Na}, \mathrm{Nm}$ and chlorophyll concentration), and (iv) NSC contents. Furthermore, we analyzed fruiting and nonfruiting shoots to clarify the scale (shoot or tree) at which the source:sink relationships regulate leaf trait acclimation to a light gradient.

\section{MATERIALS AND METHODS}

\section{Study site and meteorological conditions}

This study was conducted at the SudExpé experimental orchard in Marsillargues, France (43"66'N 4"18'E). The orchard was planted in 1998 with the 'Tentation' cultivar grafted on 'Pajam2' rootstock, which was then top grafted with 'Golden Delicious' in 2005. The experiment was performed on Solaxe trained trees (Lauri and Lespinasse, 1998). The trees were pruned and thinned according to commercial practices until the beginning of the experiment. In both years of the study (2016 and 2017), all the flowers were removed two weeks after full bloom on some of the trees ('OFF' trees), while the others were not subjected to any thinning ('ON' trees).

Light microclimate monitoring, photosynthesis measurements and sampling of plant material were performed during early July 2016, late July 2016, mid-August 2016 and late July 2017 (Table 1). Climatic variables were recorded in the vicinity of the trees by a weather station located at a height of $2.5 \mathrm{~m}$. Climatic conditions were similar in the four periods, with a warm and dry climate. The mean daily temperature and relative humidity were $24.3{ }^{\circ} \mathrm{C}$ and $57.7 \%$, respectively, with mean daily maximum and minimum temperatures of $31.5^{\circ} \mathrm{C}$ and $17.5{ }^{\circ} \mathrm{C}$ and mean daily maximum and minimum relative humidities of $86.1 \%$ and $32.9 \%$, respectively (Supplementary material Table S1). The daily photosynthetically active radiation $(P A R)$ intensity slightly differed between periods and ranged from 43.3 to $53.7 \mathrm{~mol} \mathrm{~m}^{-2} \mathrm{day}^{-1}$, likely due to variations in photoperiod (Table 1). 


\section{Experimental setup}

In this experiment, a total of 10 trees (5 ON and OFF trees) were studied. More specifically, during each period, two trees in ON conditions were considered. Only one OFF tree was considered in all periods except the fourth period, for which two trees were used (Supplementary Material Table S2). For ON trees, in 2016, three trees were followed throughout the summer (periods 1, 2 and 3). In 2017 (period 4), two other trees were sampled. These trees differed from those used in 2016 because ON trees in 2016 became OFF trees in 2017 due to biennial bearing. The crop load of each tree was estimated as the ratio of the fruit number to the trunk cross sectional area estimated in autumn. The ON trees displayed high crop loads (14.2 and 18.0 fruits $\mathrm{cm}^{-2}$ in 2016 and 2017, respectively, Supplementary Material Table S2). Conversely, OFF trees had a crop load of 0 .

All studied trees were equipped with autoleveling devices for measuring locally transmitted $P A R\left(P A R_{T}\right)$. In each period, 18 and $12 P A R$ devices were distributed within the crowns of $\mathrm{ON}$ and $\mathrm{OFF}$ trees, respectively. In total, 120 microclimate conditions were recorded during the experiment. For the ON trees, six shoots were chosen in sunlight (outer crown), six other shoots were located in the middle crown, and the final six shoots were located in shade (inner crown). For these trees, sensors were placed close to fruiting (three sensors per light condition) and nonfruiting shoots (three sensors per light condition). For the OFF trees, the same design was used for contrasting light conditions but with only four shoots per light condition. On all the trees, the devices were placed close to short (spurs, length $<5 \mathrm{~cm}$ ) and medium shoots (elongated shoots, length $>5 \mathrm{~cm}$ ).

The PAR sensors (PAR/CBE 80, Solems, Palaiseau, France) were mounted in aluminum bodies housing batteries and an electronic card dedicated to data storage and wireless communication. These homemade devices were placed on a gyroscopic mount fixed to an aluminum mast inserted into the soil. This setup enabled horizontal autoleveling for correct radiation measurements at any location within the crown. The sensors measured local $P A R_{T}$ every minute and stored 15-minute averages in the internal memory. Prior to each vegetation season, all sensors were calibrated against a Licor 190R Quantum Sensor for 24 hours for one-minute time steps $\left(\mathrm{R}^{2}>0.99\right.$, data not shown). The PAR sensors were placed less than $2 \mathrm{~cm}$ from the leafy shoots. 


\section{Leaf gas exchanges and chlorophyll measurements}

At the end of each period, just after removing the PAR sensors, the leaf with the largest surface area on each monitored shoot was chosen for gas exchange measurements $(n=120)$. Measurements were performed with a Licor 6400 system (Licor, Lincoln, USA) for two to three consecutive days in each period. Measurements were performed under nonlimiting climatic conditions in a measurement chamber $\left(P A R=1800 \mu \mathrm{mol} \mathrm{m} \mathrm{m}^{-2} \mathrm{~s}^{-1}\right.$; leaf temperature $\left(\mathrm{T}_{\text {leaf }}\right)=30{ }^{\circ} \mathrm{C}$; vapor pressure deficit $=2 \mathrm{kPa}$; air $\mathrm{CO}_{2}$ concentration $=390 \mathrm{ppmv}$; Massonnet et al. 2007). After 5-10 min of stabilization, the net $\mathrm{CO}_{2}$ assimilation $\left(A_{n e t}\right)$ was recorded during measurement sessions lasting from 7:00 AM to 12:00 AM (GMT+2). After this period, the air temperature was too high to maintain optimal conditions in the cuvette.

\section{Leaf sampling and biochemical analyses}

The shoots for which leaf gas exchange was measured were sampled. We measured the length $(L)$ and width $(W)$ of the leaf on which gas exchange measurements were performed. Its area $(A)$ was then estimated using an allometric relationship built on the trees used in this study $\left(A=0.73 \times L \times W, \mathrm{R}^{2}=0.92, \mathrm{n}=320\right)$. A proxy for chlorophyll content was measured by a SPAD-502 chlorophyll meter (Konica-Minolta, Tokyo, Japan). Then, these leaves were frozen in liquid $\mathrm{N}$ and freeze-dried, dry-weighed and finally ground prior to biochemical analyses. The main sugar and starch contents were determined after ethanol extraction by high-performance liquid chromatography (HPLC) and spectrophotometry after enzymatic digestion, respectively (Charrier and Améglio, 2011; Quentin et al., 2015). Concentrations of NSC were computed from daily calibration curves and expressed as a $\%$ of the dry matter. The total $\mathrm{N}$ concentration (in \% of dry matter) was assessed using a $\mathrm{CHN}$ analyzer (EA/NA 1110, Thermoquest). In total, 120 leaves were analyzed for NSC and N contents.

The lengths of a subset of shoots $(n=86)$ were also measured for ON and OFF trees. Shoot leaf number was estimated from shoot length assuming a linear relationship (shoot leaf number $=0.42 \times$ shoot length $\left.+4.51, \mathrm{R}^{2}=0.65, \mathrm{n}=108\right)$.

\section{Data processing and analyses}

The $L M A$ was computed from the $L D W$ and $L a$. Leaf $\mathrm{N}$ content per area unit $(\mathrm{Na}$ ) was obtained by multiplying the $L M A$ by the $\mathrm{N}$ concentration $(\mathrm{Nm})$. SPAD readings were converted into chlorophyll content per area unit $(C h l)$ using a consensus equation published by Cerovic et al. (2012), and the chlorophyll proportion per $\mathrm{Na}$ (Chl:Na) was computed. 
Mean daily $P A R_{\mathrm{T}}$ and incident $P A R\left(P A R_{\mathrm{i}}\right)$ were calculated as the average values over the last 15 days before photosynthesis measurements and sampling. Leaves were separated into three classes depending on the actual amount of intercepted radiation. In each period, the ten leaves with the highest $P A R_{\mathrm{T}}$ were assigned to the high-light group $(\mathrm{H})$, the ten leaves with the lowest values were assigned to the low-light group (L), and the other ten leaves were assigned to the medium-light group (M).

Statistical analyses were performed with R software (R Core Team, 2017). Three-way ANOVA considering light conditions (high, medium, low), crop status (ON, OFF), periods of measurements (accounting for both possible temporal and tree effects) and an interaction between light conditions and bearing status were performed for the $A_{n e t}, \mathrm{Na}, \mathrm{Chl}, \mathrm{Chl}: \mathrm{Na}$, and NSC contents. These analyses were followed by Tukey-HSD tests for pairwise comparison considering all the crop status-light combinations. Two-way ANOVA was used to analyze the consistency of light condition and crop load effects among periods by considering each period separately. The impact of local fruit on these variables was analyzed by comparing leaves belonging to fruiting and nonfruiting shoots on ON trees by two-way ANOVA considering shoot type and period effects. To estimate the effect on individual trees for each crop status, two-way ANOVAs considering tree and light conditions were performed on each date. The effect of the type of shoots (spur or elongated shoots) was tested, and no major significant differences were detected (data not shown).

Correlation analyses were conducted to assess the relationships between $A_{n e t}, \mathrm{Na}$ and $N S C$ concentration, between the subvariables involved in $N a$ variation ( $L M A, L D W, N m, L a$ ) and between all NSC forms. These correlation analyses were performed considering the whole dataset or ON and OFF trees separately.

Structural equation modeling (path analysis, Shipley 2016) was performed to analyze the relationships between NSC forms and $A_{\text {net. }}$ Previous studies (e.g., Tisné et al., 2008; Shipley, 2013) have sought the best models in terms of performance and parsimony, testing different sets of variables and structures. In our study, we chose to fit the same model structure employing the same variables to demonstrate the effects of crop status on the coefficients. This approach considers covariations among variables for computing these coefficients, in contrast to usual correlation matrix approaches. We used a model assuming (i) causal relationships between $A_{\text {net }}$ and each of the reserve and transported NSCs, i.e., starch, sorbitol and sucrose, and (ii) causal relationships between each of the reserve and transported 
NSCs and hexoses (i.e., mainly glucose and fructose), and (iii) free correlations (covariations) between starch, sorbitol and sucrose and between fructose and glucose. This analysis was performed with the Lavaan package of $\mathrm{R}$.

\section{RESULTS}

\section{Light variation with treatments and testing period}

In comparison to its value under high-light conditions, the average daily $P A R_{T}$ was reduced by approximately one-third and two-thirds in medium- and low-light conditions, respectively, regardless of the testing period (Table 1). In 2016, the highest $P A R_{T}$ values were observed in periods 1 and 2, while they were slightly lower in period 3, likely due to the shorter photoperiod. In 2016, $P A R_{T}$ in high-light conditions represented more than $60 \%$ of the PARi, while it represented between 15 and 30\% in low light conditions. In 2017 (period 4), $P A R_{T}$ values were lower than those in 2016 for all light conditions. $P A R_{T}$ represented $32 \%$ and $13 \%$ of the incoming PAR in high- and low-light conditions, respectively. This reduction in the proportion of $P A R_{T}$ compared with that of the periods in 2016 was likely associated with (1) a lack of pruning in winter 2016-2017, thus leading to greater self-shading within the canopy and (2) a deeper location of the sensors in the canopy in 2017. Finally, no major difference in $P A R_{T}$ was observed between the two crop statuses (ON and OFF trees). Only a slight but significant difference $(\mathrm{P}=0.032)$ was observed under high-light conditions due to the higher $P A R_{T}$ for OFF trees.

\section{Effect of crop status and light on carbon- and nitrogen-related variables}

$A_{\text {net }}$ was strongly affected by the crop status, with greater values for ON trees than for OFF trees regardless of the local light conditions (Fig. 1A, mean values $=13.2$ and $7.6 \mu \mathrm{mol} \mathrm{m} \mathrm{s}^{-2}$

${ }^{1}$ for ON and OFF trees, respectively). The impact of light was lower but still significant. These differences were associated with a significant decrease in $A_{\text {net }}$ for low-light conditions. The effect of light was significant for ON trees only. Nevertheless, the interaction between crop status and light conditions was statistically insignificant, meaning that this general trend of $A_{n e t}$ variation with light intensity was similar regardless of the crop status. A significant period effect was observed, but the effect of the crop status and light condition remained similar if each measurement period was considered separately (Supplementary Fig. S1). No significant individual tree effect on $A_{n e t}$ was observed in any period (Supplementary Fig. S1). 
Moreover, $A_{\text {net }}$ was similar for fruiting and nonfruiting shoots of ON trees (Fig. 1B), showing the absence of any effect of local fruit.

$\mathrm{Na}$ was significantly lower in OFF trees than ON trees (Fig. 2). This difference was quite small (1.79 and $1.59 \mathrm{~g} \mathrm{~m}^{-2}$ for ON and OFF trees) and was significant in period 1, but only if the analysis was performed for each period separately (Supplementary Fig. S2). Light also had a significant effect on $\mathrm{Na}$. This effect was associated with lower values in ON trees under low light (Fig. 2). If the four periods were considered separately, these significantly lower values were observed in periods 1 and 2 (Supplementary Fig. S2). Conversely, the decreased $\mathrm{Na}$ under low-light conditions was not observed for OFF trees, leading to a significant crop status $\times$ light effect. For $\mathrm{ON}$ trees, local fruit had no effect on $\mathrm{Na}$, consistent with the results for $A_{n e t}$ (Fig. 2A). Furthermore, as for $A_{n e t}$, no significant individual tree effect on $\mathrm{Na}$ was observed regardless of the period (Supplementary Fig. S2).

Chlorophyll contents $(C h l)$ were higher for ON trees than for OFF trees $(0.55$ vs $0.36 \mathrm{~g}$ $\mathrm{m}^{-2}$, Fig. 3A) regardless of the light. These higher values resulted from higher $N a$ values but also from a significantly higher proportion of $\mathrm{Chl}$ per $\mathrm{Na}(\mathrm{Chl}: \mathrm{Na})$ for ON trees $(26.3$ and $23.3 \%$ for ON and OFF trees, respectively, P<0.01, Fig. 3B). The effect of crop status on $C h l$ was significant in all periods, while crop status affected Chl:Na in period 4 only (Supplementary Figs. 3 and 4). This increase in Chl:Na for ON trees was significant under only low light. A slight but significant effect of light was also observed for Chl and Chl:Na. Specifically, $C h l$ had greater values under medium light than under low light, while Chl:Na had higher values under low light in ON trees only. The effects of light were observed in periods 1 and 3 for $C h l$ and $C h l: N a$, respectively. Once again, the individual tree effect remained low and was significant for $C h l$ in ON trees during period 1 only (Supplementary Figs. S3 and S4).

The crop status significantly affected starch, sorbitol and sucrose concentrations but in different ways (Fig. 4). Indeed, starch and sorbitol concentrations increased in OFF trees compared with ON trees, while sucrose concentrations slightly decreased. Moreover, the impact of crop status was greater on starch $(+78 \%$ for OFF trees) than sorbitol $(+19 \%)$. These effects of crop status on starch, sorbitol and sucrose concentrations were observed in almost all periods if considered separately (Supplementary Figs. S5, S6 and S7). The impact of light on NSC concentrations appeared lower. Light did not modify sorbitol concentration and slightly but significantly affected starch and sucrose concentrations, with a decrease under low light. These effects of light were found for almost all the measurement periods. Finally, the interaction between crop status and light was not significant for these three NSC forms. 
The effect of light was observed in some periods only (Supplementary Figs. S5, S6, and S7). Again, individual effects were not significant for these NSC forms. Regarding glucose and fructose concentrations, no significant crop status, light or interaction effects were observed (Supplementary Fig. S8). For $A_{\text {net }}$ and $N a, N S C$ concentrations were similar between fruiting and nonfruiting shoots of ON trees (Supplementary Fig. S9).

\section{Analysis of relationships between photosynthesis, light harvesting traits and NSC contents}

When the datasets from both crop statuses were considered together, a negative correlation between $A_{n e t}$ and starch was observed (Fig. 5A). Nevertheless, this relationship was not significant for OFF trees. In contrast, the relationship was significant and positive for ON trees. $\mathrm{Na}$ and $A_{\text {net }}$ were positively but slightly correlated when datasets for both crop statuses were considered together and for $\mathrm{ON}$ trees. This relationship was not significant when OFF trees were considered separately (Fig. 5B).

Crop status affected all the variables explaining variations in $\mathrm{Na}$ ( $L D W, L M A, N m$ and $\mathrm{La}$ ) (Fig. 6) but had an opposite effect on $\mathrm{Na}$. Indeed, slightly lower $\mathrm{La}$ (which increased $L M A$ and $N a$ ) and $L D W$ (which decreased $L M A$ and $N a$ ) values were observed for ON trees. Nevertheless, the crop status had a smaller effect on $L a(-14 \%)$ than on $L D W(-32 \%)$, resulting in lower LMA for ON trees than for OFF trees (Fig. $6 \mathrm{~B}, 93.5$ and $81.1 \mathrm{~g} \mathrm{~cm}^{-2}$ for OFF and ON trees, respectively). Similarly, lower $L M A$ (decreasing $\mathrm{Na}$ ) and higher $\mathrm{Nm}$ (increasing $\mathrm{Na}$ ) were observed for $\mathrm{ON}$ trees than for OFF trees. Crop status had a smaller effect on $L M A(-17 \%)$ than on $\mathrm{Nm}(+30 \%)$, consistent with a slightly higher $\mathrm{Na}$ for ON trees (Fig. 2). The crop status also affected the mean number of leaves per shoot, with greater values for OFF trees than for ON trees (8.2 vs 5.7 leaves, data not shown).

Regarding correlations with $P A R_{T}$, large variability was observed, but it depended on the variables and the crop status (Fig. 6). If data from both crop statuses were considered together, $P A R_{T}$ was not significantly correlated with $L a$ or $N m$ concentration but was significantly positively correlated with $L M A$ and $L D W$. Moreover, $P A R_{T}$ was significantly correlated with $L D W, L M A$ and $N a$ concentration for $\mathrm{ON}$ trees, while a small significant correlation was found with $L M A$ for only OFF trees.

Relationships between NSC forms and $A_{\text {net }}$ strongly depended on the crop status (ON vs OFF trees, Fig. 7). First, $A_{\text {net }}$ was strongly positively associated with sucrose and starch concentrations in $\mathrm{ON}$ trees, whereas the path coefficients related to $A_{\text {net }}$ were only slightly significant $(\mathrm{P}=0.036)$ with sucrose in $\mathrm{OFF}$ trees. In $\mathrm{ON}$ trees, the starch concentration 
covaried with sucrose and sorbitol, but this result was not observed in OFF trees. Conversely, for OFF trees, sorbitol and sucrose covaried significantly. For ON trees, the impact of sucrose concentration on hexoses was quite low, and sorbitol and starch concentrations had no impact. For OFF trees, sorbitol, sucrose and starch concentration influenced $(\mathrm{P}<0.001)$ the hexose concentrations. The correlations were positive between sorbitol, starch and hexoses and negative between sucrose and hexoses. Finally, for both crop statuses, glucose and fructose concentrations covaried. Correlation analyses (Table 2) confirmed most of the relationships observed in the path analysis. Nevertheless, for ON trees, the relationships between starch and the other NSCs (sucrose, starch) observed in the path analysis were not observed in the correlation analysis. Similarly, for OFF trees, the relationships between sucrose and glucose and between sorbitol and fructose highlighted by the path analysis were no longer observed in the correlation matrix. This phenomenon likely resulted from the structure of the path analyses, which accounted for partial correlations between the NSC forms.

\section{DISCUSSION}

\section{$A_{n e t}$ is not determined by the local fruit on highly fruited trees}

Previous results for apple trees have shown that fruit proximity can affect photosynthesis on branches subjected to different girdling practices (Poirier-Pocovi et al. 2018). In mango, Urban et al. (2003) also observed an effect of fruit presence on nearby leaf photosynthesis due to changes in $\mathrm{Na}$. In our study, local fruit presence had no effect regardless of the measured variables, consistent with results other studies (Belhassine et al. 2019). Such a discrepancy is likely associated with the very high crop loads under our conditions (more than 10 fruit $\mathrm{cm}^{-2}$ ) compared with those under usual orchard management (Wünsche et al. 2000). Under high crop load, maximal investment in $C$ assimilation and rapid export of photoassimilates from all leaves are required to sustain fruit growth at the tree scale, thus explaining the lack of differences between leaves. Thus, our results suggest a sink strength above which the global $\mathrm{C}$ demand requires maximizing $A_{n e t}$ at the canopy scale. This maximization can be achieved by optimizing both light capture and $\mathrm{C}$ assimilation, and by modifying $\mathrm{C}$ allocation as observed in this study and further discussed. 


\section{Effect of crop load status on photosynthesis optimization by acclimation of leaf $\mathrm{N}$ - related variables within trees}

Different leaf traits are key variables for describing leaf $\mathrm{C}$ function and acclimation to light gradients across a various range of plant species and are part of the so-called leaf economics spectrum (Wright et al., 2004; Niinements et al., 2015, Onoda et al., 2017). Nevertheless, the combined effects of crop load and light were not investigated in previous studies. Our study thus challenges the general applicability of that framework for systems with two contrasting source-sink relationships.

Several studies reported enhanced $A_{\text {net }}$ in ON trees compared with OFF trees (as shown by Wunsche et al. 2000 on apple, Vaast et al. 2005 on coffee, and Wu et al. 2008 on peach). Enhancing $A_{n e t}$ implies that leaves need more energy for both photochemical and biochemical processes of photosynthesis. At the leaf level, enhancing light harvesting and use can be achieved by increasing light absorption efficiency through increasing the content of light-absorbing molecules such as chlorophyll. Among the covariables that could explain the increase in $A_{n e t}$ depending on the crop status, $N a$ values were higher in $\mathrm{ON}$ trees than OFF trees. The apparent effect of the crop status ( $\mathrm{ON}$ ys OFF trees) on $\mathrm{Na}$ might be attributed to variations in $\mathrm{Nm}$. Lower $\mathrm{Nm}$ values have been reported for trees with low crop loads than for trees with high crop loads (Stander et al. (2017) for mandarin; Syvertsen et al. (2003) for orange; and Urban et al. (2004) for mango). If we consider ON trees only, our results are in agreement with those of these previous studies and consistent with the optimization hypothesis (Hollinger et al. 1996, Thornley, 1998, 2004). Nevertheless, one original aspect of our study is that such an impact of light was poorly observed for OFF trees despite the strong $P A R_{T}$ gradient. Our results thus suggest that, under the growing conditions of the study, optimal allocation of $\mathrm{N}$ within trees to maximize light harvesting and photosynthesis occurs only above a certain fruit $\mathrm{C}$ demand. This implies that trees adjust $\mathrm{N}$ absorption and further $\mathrm{N}$ allocation to leaves depending on the crop load (Ding et al., 2017). For a better understanding of the impact of $\mathrm{C}$ demand on plant $\mathrm{C}$ and $\mathrm{N}$ functions (Paul and Foyer, 2001), $\mathrm{N}$ partitioning into light harvesting, bioenergetics and biochemistry pools might require analysis. This partitioning has been documented based on the model of Niinemets and Tenhnunen (1997) for different plant functional types (see the review of Niinemets et al. 2015 for nonfruiting species, Frak et al. 2006 on walnut, and Urban et al. 2003 on mango). In that framework, our results reveal a higher concentration of $C h l$ in high cropping trees (as reported by Wünsche et al. 2005) and a higher proportion of $\mathrm{Chl}$ in $\mathrm{Na}$ in shaded leaves (as reported by Niinemets $e t$ 
al. 2004). Our study thus suggests that high fruit $\mathrm{C}$ demand might promote optimization of $A_{\text {net }}$ by increasing $\mathrm{N}$ investment in the light harvesting pool in response to a light gradient.

\section{Effect of crop load status on photosynthesis optimization by acclimation of leaf structural characteristics within trees}

Leaf structural traits such as $L M A$ are central players in the leaf economics spectrum (Wright et al., 2004; Niinements et al., 2015, Onoda et al., 2017), but the combined effects of crop load and light on these variables have been poorly investigated. In our study, significant relationships between $P A R_{T}$ and $L M A$ were found for $\mathrm{ON}$ trees only, and mean $L M A$ values were lower in ON trees. Few studies have investigated the impact of crop load on LMA (Schechter et al., 1994; Urban et al., 2004), but they did not evaluate the variation in La and $L D W$, which are used to calculate $L M A$, as performed in this study. Our results show that the relationship between $P A R_{T}$ and $L M A$ for $\mathrm{ON}$ trees was related to variations in $L D W$. The decrease in $L M A$ due to crop load could also be attributed to a stronger decrease in $L D W$ than in $L a$ for $\mathrm{ON}$ trees. A smaller investment in leaf dry matter in $\mathrm{ON}$ trees could be an adaptive trade-off to achieve satisfactory light interception efficiency, i.e., a minimal amount of biomass is invested when the fruit $\mathrm{C}$ demand is high on the plant scale. In parallel, LMA can also be considered the product of leaf thickness and leaf density; higher thickness and lower density could result in higher $A_{\text {net }}$ due to higher photosynthetic compound content and greater internal $\mathrm{CO}_{2}$ diffusion to chloroplasts, respectively (Niinemets 1999). Hence, in the present study, the increased $A_{n e t}$ in $\mathrm{ON}$ trees coupled with lower $L M A$ in $\mathrm{ON}$ trees was likely to be associated with lower density.

Consistent with other studies in fruit trees (e.g., Palmer et al. 1992 and Inglese et al., 2002), a negative relationship between vegetative primary growth and crop load was observed as the outcome of a high level of competition for $\mathrm{C}$ between vegetative and reproductive growth. This lower $\mathrm{C}$ allocation to the vegetative compartment can result in decreased light interception in high cropping trees (Wünsche et al., 2000). At the tree scale, the carbon demand of fruits in $\mathrm{ON}$ trees having this decrease in light interception could be sustained by improved radiation use efficiency through increased $\mathrm{Nm}$ and chlorophyll content and optimization of the $\mathrm{N}$ allocation to sunny leaves (Zanotelli et al., 2016). 


\section{NSC interplay within trees as affected by crop load status from a sink-driven perspective}

Several studies have reported the impact of light gradients on the spatial variability of NSCs (Lichtenthaler et al., 1981; Le Roux et al., 1999). In contrast, our results showed nearly no effect of light on the different NSC concentrations. These results suggest similar C statuses and/or export rates across the crown despite significantly different $A_{n e t}$ values. Such a result is likely related to the homogeneous distribution of the fruit within the trees for both crop statuses in our study, resulting in a homogeneous distribution of the leaf export rate.

Regulation of photosynthesis by the fruit or seed C demand has been previously observed, and two main mechanisms, i.e., stomatal closure and end-product saturation, have been discussed (Andrade et al., 2019; Gucci et al., 1995; Wünsche et al., 2005). In our study, the most marked effect was the strong depletion in leaf starch for high crop load regardless of the light (Naschitz et al., 2010; Quilot et al., 2004). In addition, the difference in the relationships between $A_{n e t}$ and starch content highlights differences in C function between the two crop statuses. In $\mathrm{ON}$ trees, the synthesized photosynthates are rapidly exported to sustain fruit growth (Breen et al., 2020; Génard et al., 2003), with C even being imported from nonbearing shoots (Walcroft et al., 2004), thus leaving a minimal amount of starch in leaves. The positive correlation observed in $\mathrm{ON}$ trees between $A_{\text {net }}$ and the starch content was more surprising. The positive correlation can be interpreted as resulting from the starch pool that is likely refilled proportionally to both the source capacity and fruit importation rate, advocating for it being considered a priority sink under high crop load, which is very scarcely observed in trees (Lescouret et al., 1998; Silpi et al., 2007). Conversely, in OFF trees, the photosynthates are oriented towards only vegetative growth. In these trees, the leaf starch pool was filled due to low $\mathrm{C}$ demand at the tree scale. This starch pool was likely dedicated to reserves for sustaining further organ primary and/or secondary vegetative growth (root, shoots, and branches). Finally, this starch accumulation might downregulate $A_{\text {net }}$ (Nebauer et al., 2011; Poirier-Pocovi et al., 2018; Urban et al. 2004; 2007), thus canceling its spatial variability.

Similar to starch, light had nearly no effect on leaf sucrose and hexose contents. Nevertheless, sorbitol content was lower in ON trees than OFF trees, suggesting a higher use rate for fueling fruit growth (Pallas et al., 2018). Moreover, the relationships among the NSC and $A_{n e t}$ differed between the ON and OFF trees, as shown by the path and correlation analyses, revealing different $\mathrm{C}$ allocation patterns for the two crop loads. In ON trees, the pattern that could be drawn was a major allocation of photosynthates to transport to outside 
the leaf, especially for sucrose and, to a lesser extent, sorbitol. The relationships among sucrose, glucose and fructose were also consistent with the known pathway of sucrose biosynthesis. The relationships between $A_{n e t}$ and starch and among starch, sorbitol and sucrose reveal the central role of the latter group as an intermediary pool directly fueled by photosynthesis. In contrast, in OFF trees, the path model showed a feedback loop between sucrose and sorbitol, with the latter being related to both glucose and fructose, which in turn were related to sucrose. Such cyclic interactions might reflect other roles of sucrose and sorbitol as temporary storage forms when the leaf starch pool has likely reached high levels for further use in vegetative growth or storage (Escobar-Gutierrez and Gaudillère, 1996; Genard et al., 2003).

\section{CONCLUSIONS}

Although previous studies have investigated the impact of light microclimate and fruit load on leaf traits (functional and structural), none of them have analyzed their combined effects. In this context, our study reports original results and demonstrates that crop status has a greater influence than local light or local fruit on all the measured traits. Moreover, our study clearly shows that the intensity of leaf acclimation to light strongly depends on the carbon demand at the tree scale. Indeed, acclimation of photosynthesis to light was mainly observed for ON trees, which was achieved mainly by increased light capture efficiency, implying higher leaf $\mathrm{N}$ and lower LMA. Conversely, low $\mathrm{C}$ demand, as in OFF trees, is thought to disrupt the optimal distribution of resources by modifying the interplay among NSCs. These experimental results have potential implications for shifting modeling approaches towards a more mechanistic representation of optimal strategies between $\mathrm{C}$ and $\mathrm{N}$ within-tree allocations depending on the crop load. Our study also supports a consistent description of the possible role of starch in regulating photosynthetic activity and its spatial variability according to crop load. Under high crop loads, starch could be one of the priority sinks. Under high crop loads, high starch levels promote the optimization of photosynthesis and related traits, while under low crop load, high starch levels tend to downregulate photosynthetic activity. Moreover, sorbitol and sucrose play major roles in the transport of carbohydrates when fruit demand is high, while they serve as temporary reserves under low crop loads in apple trees. 


\section{DATA AVAILABILITY}

The data that support the findings of this study are openly available in a Data INRAE repository (doi: XXXXXX to be completed).

\section{ACKNOWLEDGMENTS}

This study was funded by the ANR-DFG “Alternapp" project (ANR-14-CE35-0001-01). The authors acknowledge SILVATECH (ANR-11-LABX-0002-01) from UMR 1434 SILVA, 1136 IAM, 1138 BEF and 4370 EA LERMAB of the research center INRAE Nancy-Lorraine for the leaf nitrogen analyses. Dr Marc Saudreau and Dr André Lacointe (UMR 0547 PIAF) are thanked for insightful advice regarding light sensor positioning in the field and for useful comments on the manuscript, respectively. Xavier Le Roux (Fondation pour la Recherche sur la Biodiversité) is acknowledged for having initiated questioning the within-tree variability of leaf function at the PIAF unit. Dr Farés Belhassine is also thanked for providing additional data used to build allometric relationships.

\section{AUTHOR CONTRIBUTIONS}

$\mathrm{JN}$ and $\mathrm{BP}$ designed the experiment. $\mathrm{AM}$ and $\mathrm{JN}$ installed and monitored the functioning of the PAR sensors. SM, BP and SB performed the field measurements, and BSJ and SB performed the biochemical analyses. BP and JN performed the statistical analyses and wrote the manuscript. EC reviewed and improved the manuscript. 


\section{REFERENCES}

Andrade D, Covarrubias MP, Benedetto G, Pereira EG, Almeida AM. 2019. Differential source-sink manipulation affects leaf carbohydrate and photosynthesis of early- and late-harvest nectarine varieties. Theoretical and Experimental Plant Physiology 31, 341-356.

Anthony B, Serra S, Musacchi S. 2019. Optimizing Crop Load for New Apple Cultivar: "WA38". Agronomy 9, 107.

Bairam E, leMorvan C, Delaire M, Buck-Sorlin G. 2019. Fruit and Leaf Response to Different SourceSink Ratios in Apple, at the Scale of the Fruit-Bearing Branch. Frontiers in Plant Science 10.1039.

Belhassine F, Martinez S, Bluy S, Fumey D, Kelner JJ, Costes E, Pallas B. 2019. Impact of Within-Tree Organ Distances on Floral Induction and Fruit Growth in Apple Tree: Implication of Carbohydrate and Gibberellin Organ Contents. Frontiers in Plant Science 10. 1233.

Bloom AJ. 1985. Wild and cultivated barleys show similar affinities for mineral nitrogen. Oecologia 65, 555-557.

Breen K, Tustin S, Palmer J, Boldingh H, Close D. 2020. Revisiting the role of carbohydrate reserves in fruit set and early-season growth of apple. Scientia Horticulturae 261.

Buckley TN, Cescatti A, Farquhar GD. 2013. What does optimization theory actually predict about crown profiles of photosynthetic capacity when models incorporate greater realism? Plant Cell and Environment 36, 1547-1563.

Cerovic ZG, Masdoumier G, Ben Ghozlen N, Latouche G. 2012. A new optical leaf-clip meter for simultaneous non-destructive assessment of leaf chlorophyll and epidermal flavonoids. Physiologia Plantarum 146, 251-260.

Charrier G, Améglio T. 2011. The timing of leaf fall affects cold acclimation by interactions with air temperature through water and carbohydrate contents. Environmental and Experimental Botany 72, 351-357.

Davi H, Dufrêne E, Granier A, Le Dantec V, Barbaroux C, François C, Bréda N. 2005. Modelling carbon and water cycles in a beech forest Part II.: Validation of the main processes from organ to stand scale. Ecological Modelling 185, 387-405.

Ding N, Chen Q, Zhu Z, Peng L, Ge S, Jiang Y. 2017. Effects of crop load on distribution and utilization of $13 \mathrm{C}$ and $15 \mathrm{~N}$ and fruit quality for dwarf apple trees. Scientific Reports 7, 14172.

Escobar-Gutierrez AJ, Gaudillere JP. 1996. Distribution, metabolism and role of sorbitol in higher plants. A review. Agronomie 16, 281-298.

Farquhar GD, von Caemmerer Sv, Berry J. 1980. A biochemical model of photosynthetic CO2 assimilation in leaves of C3 species. Planta 149, 78-90.

Frak E, Le Roux X, Millard P, Guillaumie S, Wendler R. 2006. Nitrogen availability, local light regime and leaf rank effects on the amount and sources of $\mathrm{N}$ allocated within the foliage of young walnut (Juglans nigra $\times$ regia) trees. Tree Physiology 26, 43-49.

Franklin 0.2007. Optimal nitrogen allocation controls tree responses to elevated CO2. New Phytologist 174, 811-822.

Génard M, Lescourret F, Gomez L, Habib R. 2003. Changes in fruit sugar concentrations in response to assimilate supply, metabolism and dilution: a modeling approach applied to peach fruit (Prunus persica). Tree Physiology 23, 373-385.

Gucci R, Grappadelli LC, Tustin S, Ravaglia G. 1995. The effect of defruiting at different stages of fruit-development on leaf photosynthesis of golden-delicious apple. Tree Physiology 15, 35-40.

Hikosaka K. 2014. Optimal nitrogen distribution within a leaf canopy under direct and diffuse light. Plant Cell and Environment 37, 2077-2085.

Hollinger DY. 1996. Optimality and nitrogen allocation in a tree canopy. Tree Physiology 16, 627-634. Inglese P, Caruso T, Gugliuzza G, Pace LS. 2002. Crop Load and Rootstock Influence on Dry Matter Partitioning in Trees of Early and Late Ripening Peach Cultivars. Journal of the American Society for Horticultural Science 127, 825. 
Le Roux X, Bariac T, Sinoquet H, Genty B, Piel C, Mariotti A, Girardin C, Richard P. 2001. Spatial distribution of leaf water-use efficiency and carbon isotope discrimination within an isolated tree crown. Plant Cell and Environment 24, 1021-1032.

Le Roux X, Sinoquet H, Vandame M. 1999. Spatial distribution of leaf dry weight per area and leaf nitrogen concentration in relation to local radiation regime within an isolated tree crown. Tree Physiology 19, 181-188.

Lescourret F, Ben Mimoun M, Génard M. 1998. A simulation model of growth at the shoot-bearing fruit level: I. Description and parameterization for peach. European Journal of Agronomy 9, 173-188. Lichtenthaler HK, Buschmann C, Döll M, Fietz H-J, Bach T, Kozel U, Meier D, Rahmsdorf U. 1981. Photosynthetic activity, chloroplast ultrastructure, and leaf characteristics of high-light and low-light plants and of sun and shade leaves. Photosynthesis Research 2, 115-141.

Makela A, Valentine HT, Helmisaari H-S. 2008. Optimal co-allocation of carbon and nitrogen in a forest stand at steady state. New Phytologist 180, 114-123.

Massonnet C, Costes E, Rambal S, Dreyer E, Regnard JL. 2007. Stomatal Regulation of

Photosynthesis in Apple Leaves: Evidence for Different Water-use Strategies between Two Cultivars. Annals of Botany 100, 1347-1356.

McMurtrie RE, Dewar RC. 2011. Leaf-trait variation explained by the hypothesis that plants maximize their canopy carbon export over the lifespan of leaves. Tree Physiology 31, 1007-1023. Monselise SP, Goldschmidt EE. 1982. Alternate bearing in fruit trees. Horticultural reviews 4, 128173.

Montpied P, Granier A, Dreyer E. 2009. Seasonal time-course of gradients of photosynthetic capacity and mesophyll conductance to $\mathrm{CO}(2)$ across a beech (Fagus sylvatica L.) canopy. Journal of experimental Botany 60, 2407-2418.

Mooney HA, Gulmon SL. 1979. Environmental and Evolutionary Constraints on the Photosynthetic Characteristics of Higher Plants. In: Solbrig OT, Jain S, Johnson GB, Raven PH, eds. Topics in Plant Population Biology. London: Macmillan Education UK, 316-337.

Naschitz S, Naor A, Genish S, Wolf S, Goldschmidt EE. 2010. Internal management of non-structural carbohydrate resources in apple leaves and branch wood under a broad range of sink and source manipulations. Tree Physiology 30, 715-727.

Nebauer SG, Renau-Morata B, Guardiola JL, Molina RV. 2011. Photosynthesis down-regulation precedes carbohydrate accumulation under sink limitation in Citrus. Tree Physiology 31, 169-177. Niinemets U. 2012. Optimization of foliage photosynthetic capacity in tree canopies: towards identifying missing constraints. Tree Physiology 32, 505-509.

Niinemets Ü. 1999. Research review. Components of leaf dry mass per area - thickness and density - alter leaf photosynthetic capacity in reverse directions in woody plants. New Phytologist 144, $35-$ 47.

Niinemets Ü, Keenan TF, Hallik L. 2015. A worldwide analysis of within-canopy variations in leaf structural, chemical and physiological traits across plant functional types. New Phytologist 205, 973993.

Niinemets U, Kull O, Tenhunen JD. 2004. Within-canopy variation in the rate of development of photosynthetic capacity is proportional to integrated quantum flux density in temperate deciduous trees. Plant Cell and Environment 27, 293-313.

Niinemets Ü, Tenhunen JD. 1997. A model separating leaf structural and physiological effects on carbon gain along light gradients for the shade-tolerant species Acer saccharum. Plant, Cell and Environment 20, 845-866.

Onoda Y, Wright IJ, Evans JR, Hikosaka K, Kitajima K, Niinemets Ü, Poorter H, Tosens T, Westoby M. 2017. Physiological and structural tradeoffs underlying the leaf economics spectrum. New Phytologist 214, 1447-1463.

Pallas B, Bluy S, Ngao J, Martinez S, Clément-Vidal A, Kelner J-J, Costes E. 2018. Growth and carbon balance are differently regulated by tree and shoot fruiting contexts: an integrative study on apple genotypes with contrasted bearing patterns. Tree Physiology 38, 1395-1408 
Palmer JW. 1992. Effects of varying crop load on photosynthesis, dry-matter production and partitioning of crispin/m.27 apple-trees. Tree Physiology 11, 19-33.

Palmer JW, Cai YL, Edjamo Y. 1991. Effect of part-tree flower thinning on fruiting, vegetative growth and leaf photosynthesis in cox orange pippin apple. Journal of Horticultural Science 66, 319-325.

Paul MJ, Foyer CH. 2001. Sink regulation of photosynthesis. Journal of experimental Botany 52, 1383-1400.

Poirier-Pocovi M, Lothier J, Buck-Sorlin G. 2018. Modelling temporal variation of parameters used in two photosynthesis models: influence of fruit load and girdling on leaf photosynthesis in fruitbearing branches of apple. Annals of Botany 121, 821-832.

Poorter H, Niinemets Ü, Ntagkas N, Siebenkäs A, Mäenpää M, Matsubara S, Pons T. 2019. A metaanalysis of plant responses to light intensity for 70 traits ranging from molecules to whole plant performance. New Phytologist 223, 1073-1105.

Prieto JA, Louarn G, Pena JP, Ojeda H, Simonneau T, Lebon E. 2012. A leaf gas exchange model that accounts for intra-canopy variability by considering leaf nitrogen content and local acclimation to radiation in grapevine (Vitis vinifera L.). Plant Cell and Environment 35, 1313-1328.

Quentin AG, Close DC, Hennen L, Pinkard EA. 2013. Down-regulation of photosynthesis following girdling, but contrasting effects on fruit set and retention, in two sweet cherry cultivars. Plant Physiology and Biochemistry 73, 359-367.

Quentin AG, Pinkard EA, Ryan MG, et al.. 2015. Non-structural carbohydrates in woody plants compared among laboratories. Tree Physiology 35, 1146-1165.

Quilot B, Génard M, Kervella J. 2004. Leaf light-saturated photosynthesis for wild and cultivated peach genotypes and their hybrids: A simple mathematical modelling analysis. The Journal of Horticultural Science and Biotechnology 79, 546-553.

R Developpment Core Team. 2017. R: A language and environment for statistical computing. Vienna, Austria: R Foundation for Statistical Computing.

Saa S, Brown PH. 2014. Fruit presence negatively affects photosynthesis by reducing leaf nitrogen in almond. Functional Plant Biology 41, 884-891.

Schechter I, Proctor JTA, Elfving DC. 1994. Apple Fruit Removal and Limb Girdling Affect Fruit and Leaf Characteristics. Journal of the American Society for Horticultural Science 119, 157.

Sheen J. 1994. Feedback-control of gene-expression. Photosynthesis Research 39, 427-438.

Shipley B. 2013. The AIC model selection method applied to path analytic models compared using a d-separation test. Ecology 94, 560-564.

Shipley B, ed. 2016. Cause and Correlation in Biology: A Users Guide to Path Analysis, Structural Equations and Causal Inference with $R$. Cambridge: Cambridge University Press.

Silpi U, Lacointe A, Kasempsap P, Thanysawanyangkura S, Chantuma P, Gohet E, Musigamart N, Clément A, Améglio T, Thaler P. 2007. Carbohydrate reserves as a competing sink: evidence from tapping rubber trees. Tree Physiology 27, 881-889.

Stander OPJ, Barry GH, Cronje PJR. 2017. Fruit-load-induced starch accumulation causes leaf chlorosis in "off" 'Nadorcott' mandarin trees. Scientia Horticulturae 222, 62-68.

Syvertsen JP, Goni C, Otero A. 2003. Fruit load and canopy shading affect leaf characteristics and net gas exchange of 'Spring' navel orange trees. Tree Physiology 23, 899-906.

Thornley JHM. 2004. Acclimation of photosynthesis to light and canopy nitrogen distribution: an interpretation. Annals of Botany 93, 473-475.

Tisné S, Reymond M, Vile D, Fabre J, Dauzat M, Koornneef M, Granier C. 2008. Combined Genetic and Modeling Approaches Reveal That Epidermal Cell Area and Number in Leaves Are Controlled by Leaf and Plant Developmental Processes in Arabidopsis. Plant Physiology 148, 1117-1127.

Urban L, Alphonsout L. 2007. Girdling decreases photosynthetic electron fluxes and induces sustained photoprotection in mango leaves. Tree Physiology 27, 345-352.

Urban L, Le Roux X, Sinoquet H, Jaffuel S, Jannoyer M. 2003. A biochemical model of photosynthesis for mango leaves: evidence for the effect of fruit on photosynthetic capacity of nearby leaves. Tree Physiology 23, 289-300. 
Urban L, Lechaudel M, Lu P. 2004. Effect of fruit load and girdling on leaf photosynthesis in Mangifera indica L. Journal of Experimental Botany 55, 2075-2085.

Vaast P, Angrand J, Franck N, Dauzat J, Genard M. 2005. Fruit load and branch ring-barking affect carbon allocation and photosynthesis of leaf and fruit of Coffea arabica in the field. Tree Physiology 25, 753-760.

Valantin M, Gary C, Vaissiere BE, Tchamitchian M, Bruneli B. 1998. Changing sink demand affects the area but not the specific activity of assimilate sources in cantaloupe (Cucumis melo L.). Annals of Botany 82, 711-719.

Walcroft AS, Lescourret F, Genard M, Sinoquet H, Le Roux X, Dones N. 2004. Does variability in shoot carbon assimilation within the tree crown explain variability in peach fruit growth? Tree Physiology 24, 313-322.

Wright IJ, Reich PB, Westoby M, et al. 2004. The worldwide leaf economics spectrum. Nature 428, 821-827.

Wu BH, Huang HQ, Fan PG, Li SH, Liu GJ. 2008. Photosynthetic Responses to Sink-Source Manipulation in Five Peach Cultivars Varying in Maturity Date. Journal of the American Society for Horticultural Science 133, 278.

Wunsche JN, Greer DH, Laing WA, Palmer JW. 2005. Physiological and biochemical leaf and tree responses to crop load in apple. Tree Physiology 25, 1253-1263.

Wunsche JN, Palmer JW, Greer DH. 2000. Effects of crop load on fruiting and gas-exchange characteristics of 'Braeburn'/M.26 apple trees at full canopy. Journal of the American Society for Horticultural Science 125, 93-99.

Zanotelli D, Scandellari F, Bastos de Melo W, Cassol P, Tagliavini M. 2016. Effect of fruit load on the photosynthetic capacity and on the ecological light use efficiency of an apple orchard. Acta

Horticulturae 1130, 25-32. 


\section{TABLES}

Table 1. Mean values of daily incoming photosynthetically active radiation (PARi, +/- standard deviation among days) and mean values of transmitted PAR for the two crop statuses ('ON' and 'OFF') and the three light environments in the four measurement periods ( $+/-$ standard deviation among leaves of each light/crop load environments).

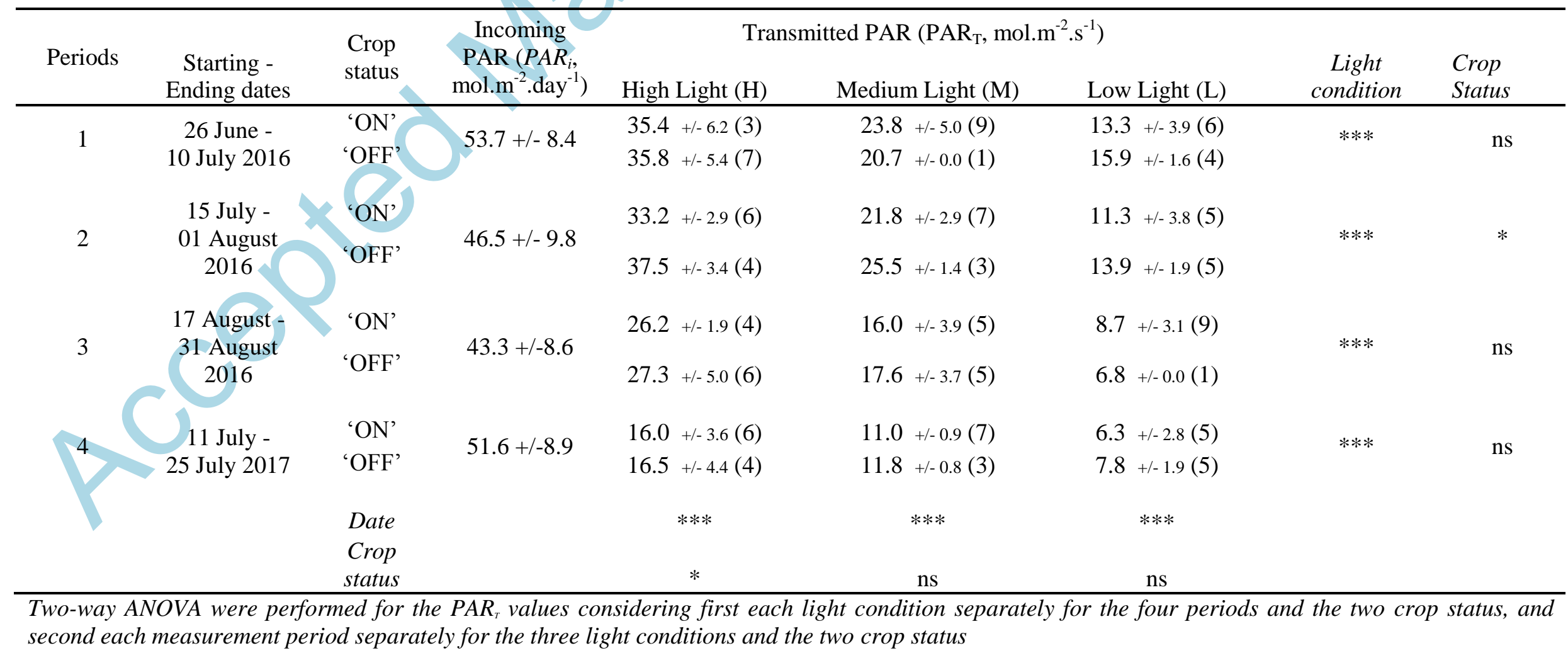


Table 2. Correlation coefficient and associated level of significance between the non-structural carbohydrates forms and net carbon assimilation $\left(A_{\text {net }}\right)$. The upper and lower panels correspond for 'OFF' and 'ON' trees, respectively.

\begin{tabular}{lccccccc}
\hline & Glucose & Fructose & Sucrose & Sorbitol & Starch & $A_{n e t}$ \\
\hline Glucose & & $\mathbf{0 . 7 8 * * *}$ & $\mathrm{ns}$ & $\mathbf{0 . 5 6 * * *}$ & $0.36 *$ & $\mathrm{~ns}$ & \\
Fructose & $\mathbf{0 . 9 2 * * *}$ & & $-0.48 * *$ & $\mathrm{~ns}$ & $0.35 *$ & $\mathrm{~ns}$ & 'OFF' \\
Sucrose & $-0.30 * *$ & $-0.29 *$ & & $\mathbf{0 . 5 9} * * *$ & $\mathrm{~ns}$ & $0.35 *$ & trees \\
Sorbitol & $\mathrm{ns}$ & $\mathrm{ns}$ & $\mathrm{ns}$ & & $\mathrm{ns}$ & $\mathrm{ns}$ & $\mathrm{ns}$ \\
Starch & $\mathrm{ns}$ & $\mathrm{ns}$ & $\mathrm{ns}$ & $\mathrm{ns}$ & & & \\
$A_{\text {net }}$ & $\mathrm{ns}$ & $-0.27 *$ & $\mathbf{0 . 7 5 * * *}$ & $\mathrm{ns}$ & $\mathbf{0 . 6 1} * * *$ & &
\end{tabular}

*** significant at $P<0.001$, ** significant at $0.001<P<0.01$, * significant at $0.01<P<0.05$, ns non significant. 


\section{FIGURE LEGENDS}

Figure 1. A. Boxplot representation of net carbon assimilation $\left(A_{n e t}\right)$ for the two crop statuses ('ON' and 'OFF') and the three light conditions (H: High, M: Medium, L: Low) considering together the four measurement dates. B. Boxplot representation of $A_{n e t}$ in the fruiting and non-fruiting shoots in ' $\mathrm{ON}$ ' trees considering together the four measurement dates. In $\mathrm{A}$, a three-way ANOVA with crop status, light condition and period effects, and the light condition $\times$ crop status interaction was performed. This analysis was followed by a pair-wise Tukey test considering all the crop status-light condition combinations and letters indicate significant differences among groups at $\mathrm{P}<0.05$. In $\mathrm{B}$, a two-way ANOVA with fruit presence and period effects was performed. $* * *$ significant at $\mathrm{P}<0.001$, ** significant at $0.001<\mathrm{P}<0.01$ and ns non-significant.

Figure 2. A. Boxplot representation of leaf nitrogen concentration per area unit $(\mathrm{Na})$ for the two crop statuses ('ON' and 'OFF') and the three light conditions (H: High, M: Medium, L: Low) considering together the four measurement dates. B. Boxplot representation of $\mathrm{Na}$ in the fruiting and non-fruiting shoots in ' $\mathrm{ON}$ ' trees considering together the four measurement dates. In A, a three-way ANOVA with crop status, light conditions and period effects, and the light condition $\times$ crop status interaction was performed. This analysis was followed by a pairwise Tukey test considering all the crop status-light condition combinations and letters indicate significant differences among groups at $\mathrm{P}<0.05$. In $\mathrm{B}$, a two-way ANOVA with fruit presence and period effects was performed. $* * *$ significant at $\mathrm{P}<0.001$, ** significant at $0.001<\mathrm{P}<0.01, *$ significant at $0.05<\mathrm{P}<0.01$ and ns non-significant.

Figure 3. Boxplot representations of chlorophyll concentration per area unit $(C h l)$ and of chlorophyll proportion per leaf nitrogen area $(\mathrm{Chl:Na})$ for the two crop statuses ('ON' and 'OFF') and the three light conditions (H: High, M: Medium, L: Low) in the four measurement periods. For each period, a two-way ANOVA with crop status, light conditions and the interaction between light condition and crop status was performed. $* * *$ significant at $\mathrm{P}<0.001$, ** significant at $0.001<\mathrm{P}<0.01$, * significant at $0.01<\mathrm{P}<0.05$, and ns nonsignificant. This analysis was followed by a pair-wise Tukey test considering all the crop status-light condition combinations and letters indicate significant differences among groups at $\mathrm{P}<0.05$.

Figure 4. Boxplot representations of starch (A), sorbitol (B), sucrose (C) concentrations in leaves for the two crop statuses ('ON' and 'OFF') and the three light conditions (H: High, M: Medium, L: Low) considering together the four measurement dates. In A, B and C threeway ANOVA with crop status, light conditions and period effects, and the light condition $\times$ crop status interaction was performed. These analyses were followed by pair-wise Tukey tests considering all the crop status-light condition combinations and letters indicate significant differences among groups at $\mathrm{P}<0.05$. $* * *$ significant at $\mathrm{P}<0.001$, ** significant at $0.001<\mathrm{P}<0.01, *$ significant at $0.05<\mathrm{P}<0.01$ and ns non-significant.

Figure 5. Correlations between net carbon assimilation $\left(A_{n e t}\right)$ and starch concentration in leaves (A) and between $A_{n e t}$ and leaf nitrogen concentration per area unit $(\mathrm{Na}, \mathrm{B})$. Dotted lines represent the linear regression considering both crop statuses (' $O N$ ' and 'OFF') and blue lines represent the linear regression considering ' $\mathrm{ON}$ ' trees, only. $\mathrm{R}^{2}$ values and the level 
of significance of the correlations are represented in the top left corner of each graph. *** significant at $\mathrm{P}<0.001, * *$ significant at $0.001<\mathrm{P}<0.01$ and ns non-significant.

Figure 6. Correlations between locally transmitted photosynthetically active radiation $\left(\mathrm{PAR}_{\mathrm{T}}\right)$ and leaf dry weight $(L D W, \mathrm{~A})$, leaf mass area $(L M A, \mathrm{~B})$, nitrogen concentration per mass unit in leaves $(\mathrm{Nm}, \mathrm{C})$ and individual leaf area $(\mathrm{La}, \mathrm{D})$. Dotted lines represent the linear regression considering both crop statuses ('ON' and 'OFF'), blue lines represent the linear regression considering $\mathrm{ON}$ trees, only and red lines represent the linear regression considering ' $\mathrm{OFF}$ ' trees, only. $\mathrm{R}^{2}$ values and the level of significance of the correlations are represented in each sub-figure legend. $* * *$ significant at $\mathrm{P}<0.001$, ** significant at $0.001<\mathrm{P}<0.01$ and $\mathrm{ns}$ non-significant. Dashed red and blue lines represent the mean values observed for 'OFF' and 'ON' trees, respectively. A one-way ANOVA was used to estimate the significance of the crop status effect. The level of significance of the effect of the crop status is represented in the first line of the sub-figures legend.

Figure 7. Results of the path analysis performed on net carbon assimilation $\left(A_{\text {net }}\right)$ and nonstructural carbohydrate concentrations in leaves on ' $\mathrm{ON}$ ' and 'OFF' trees. On these graphs, only the significant relationships of the model are represented. Single-headed arrows represent causal relationships and double-headed arrows represent free correlations. Normalized path coefficients together with their significance level were represented above each arrow. $* * *$ significant at $\mathrm{P}<0.001$, ** significant at $0.001<\mathrm{P}<0.01$, * significant at $0.05<\mathrm{P}<0.01$. 


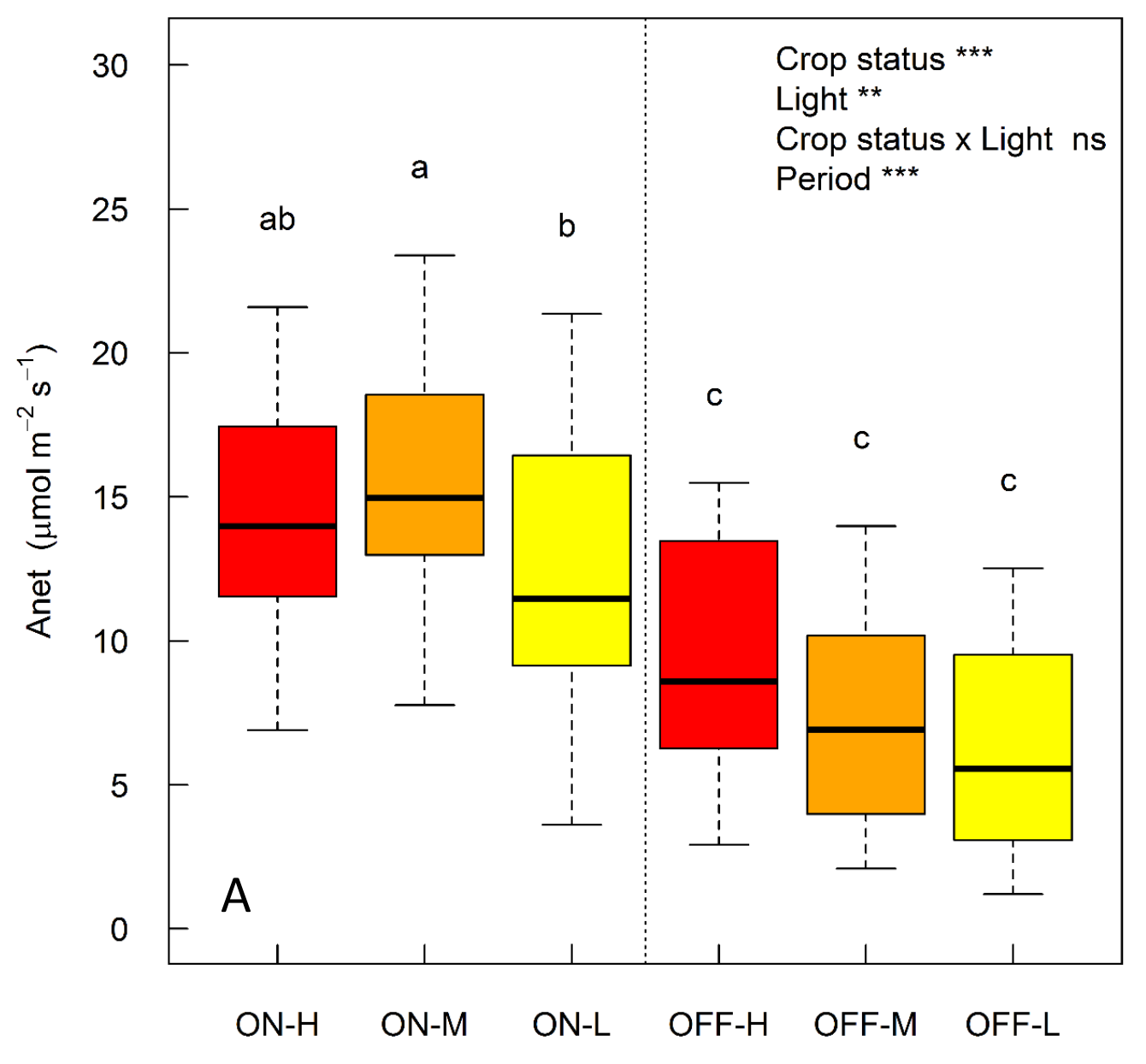

Fig. 1.

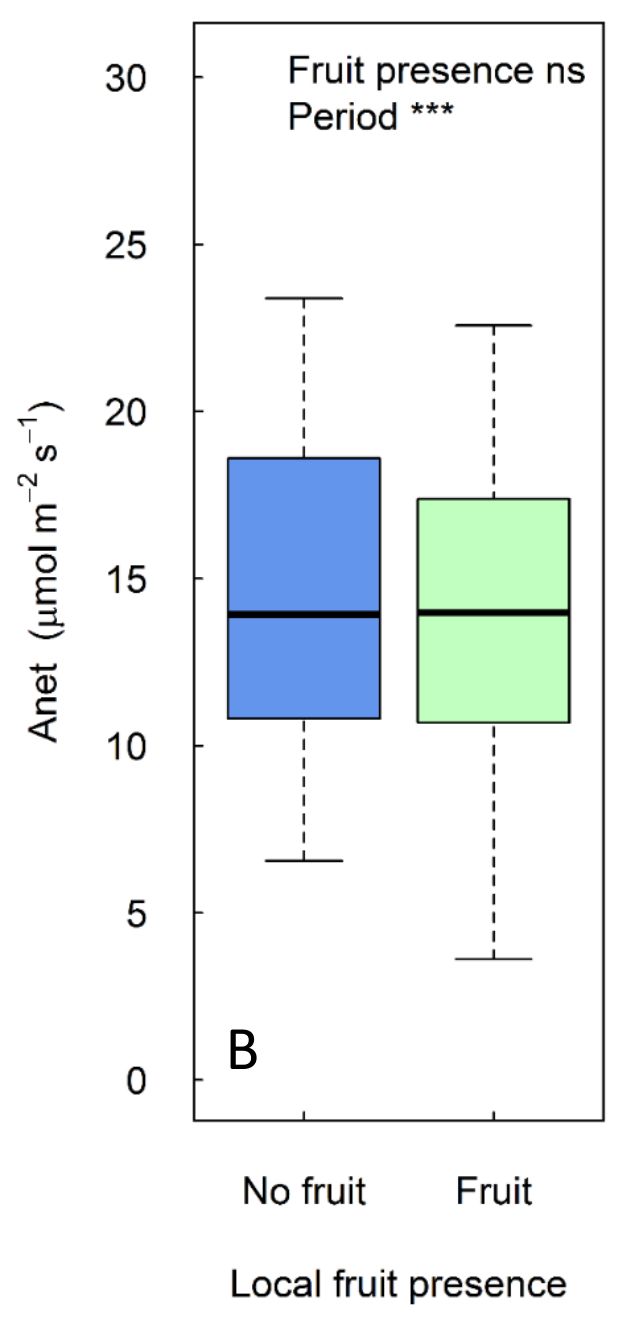




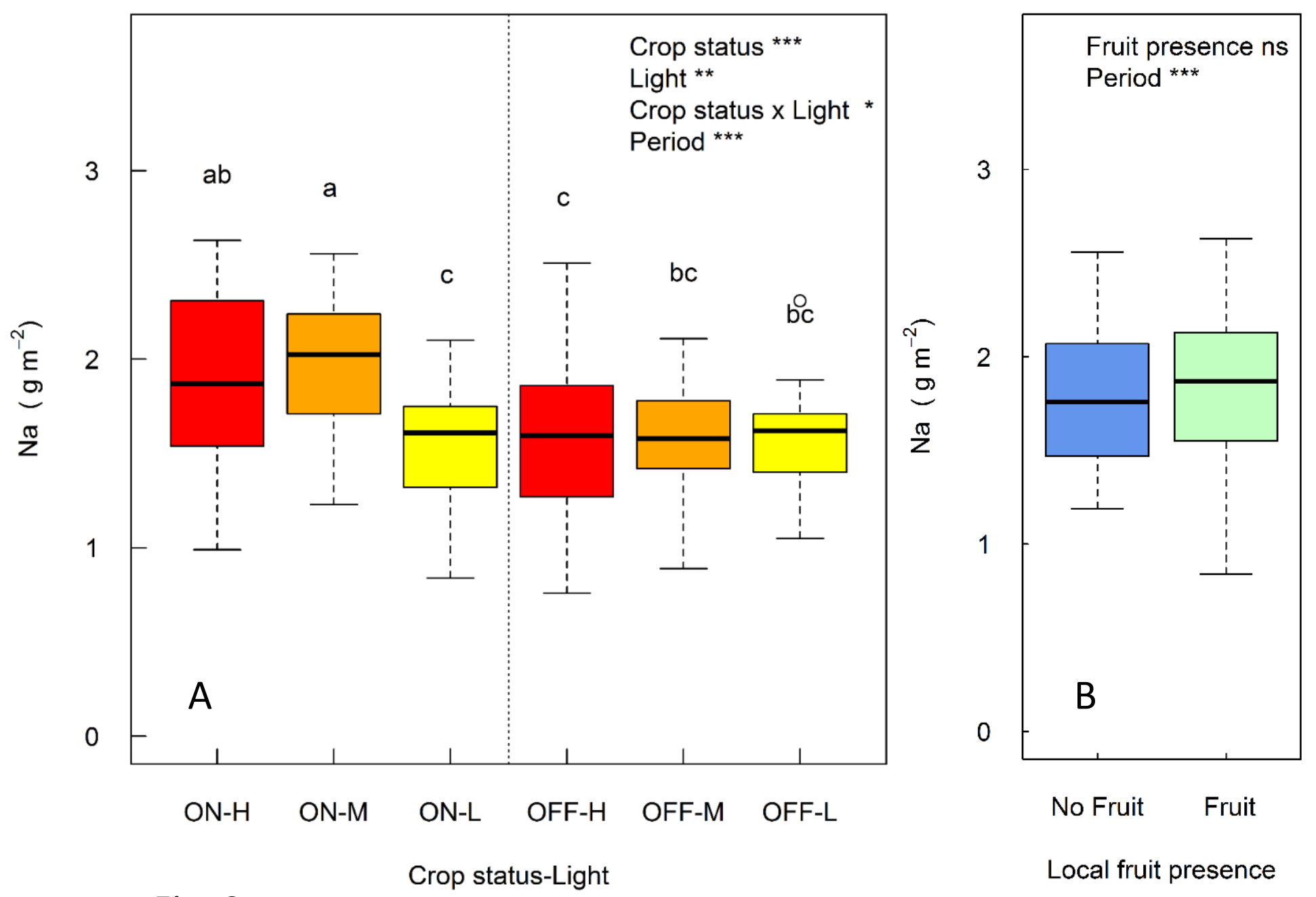

Fig. 2. 

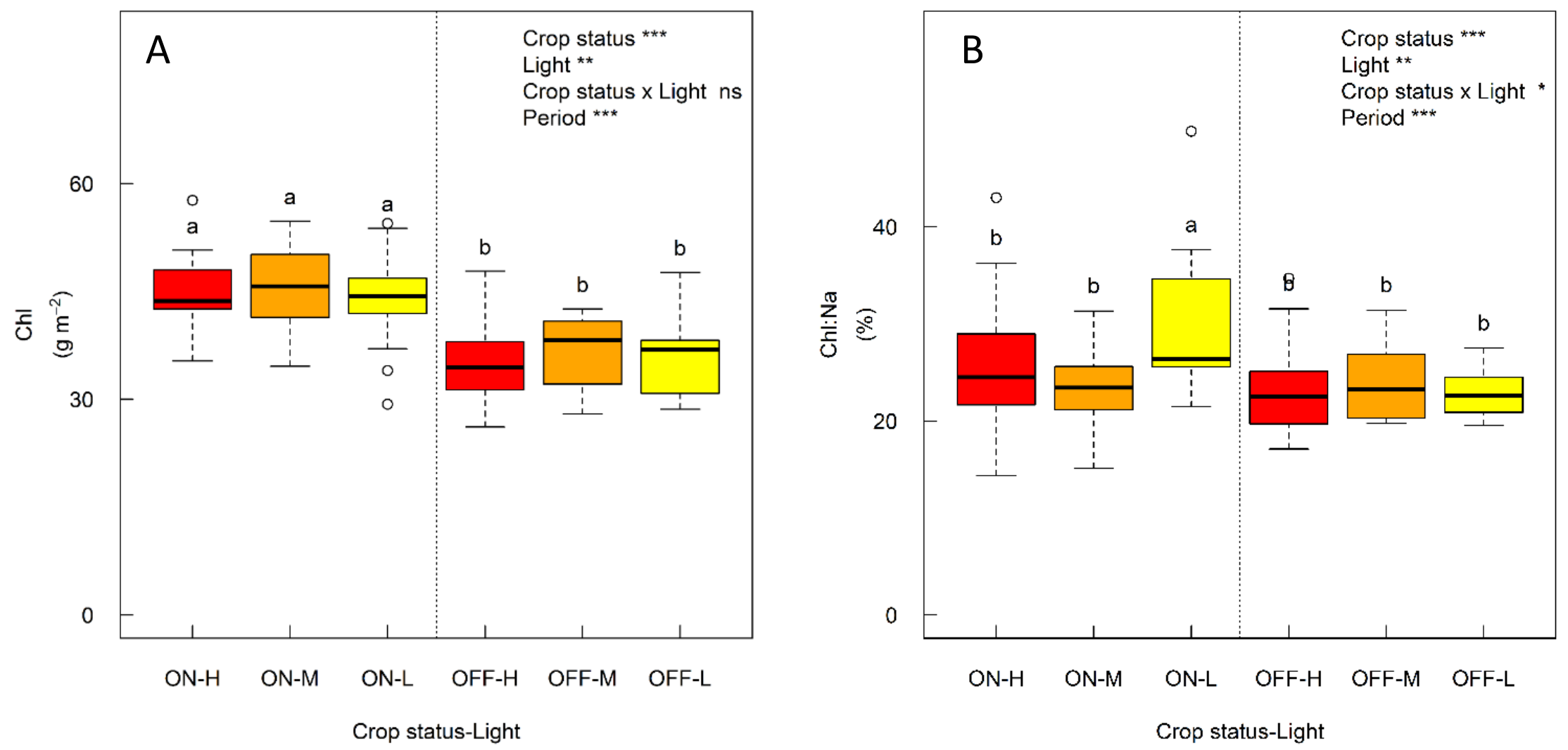

Fig. 3. 


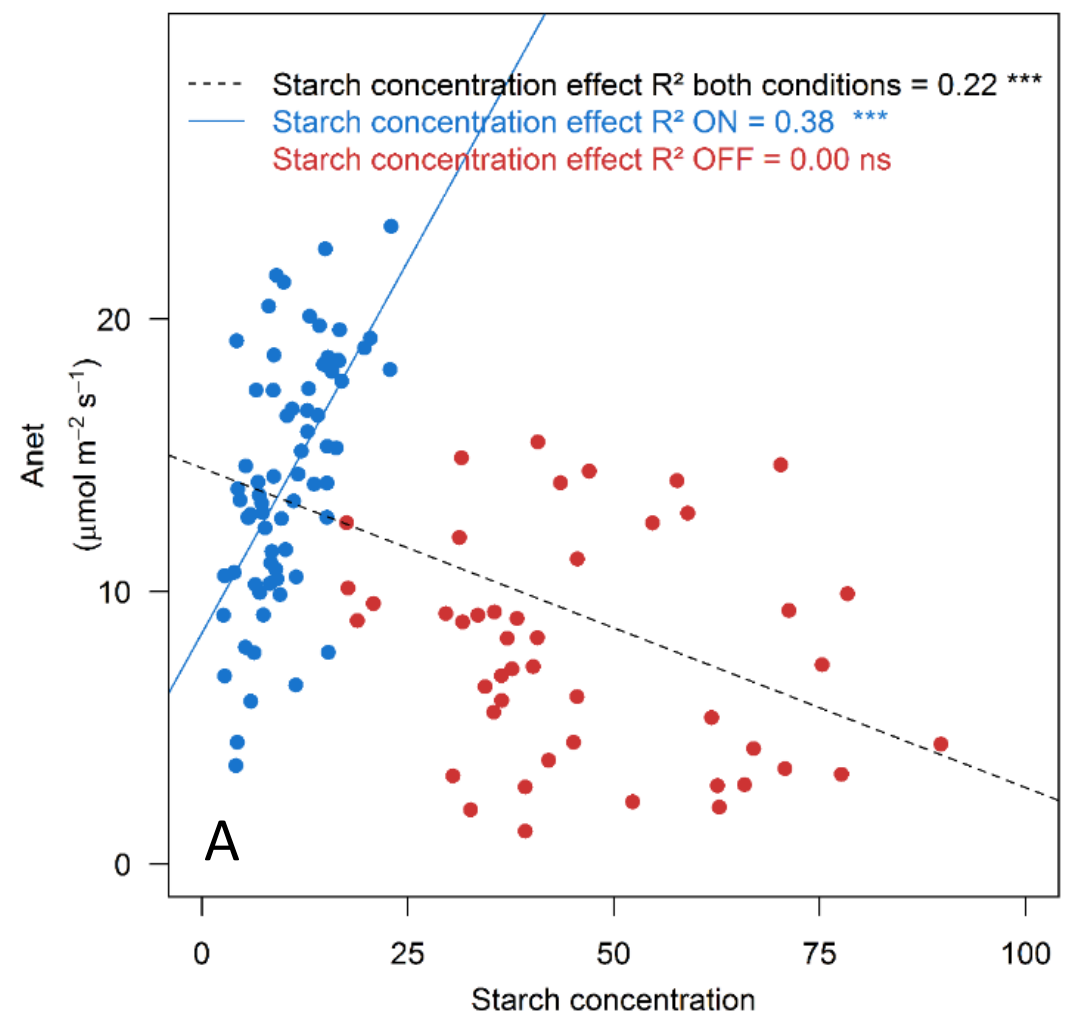

$\left(\mathrm{mg} \mathrm{g}^{-1}\right)$

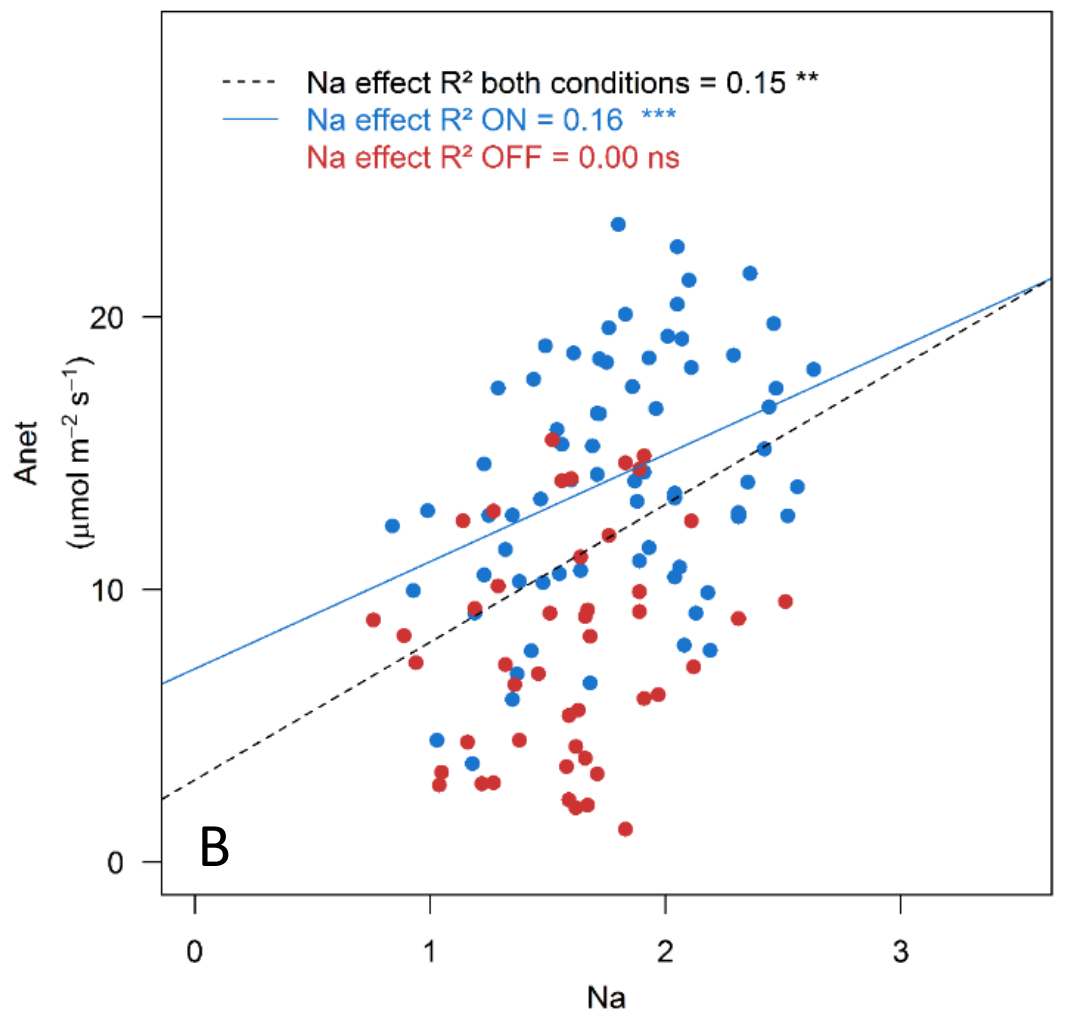

$\left(\mathrm{g} \mathrm{m}^{-2}\right)$

Fig. 5. 

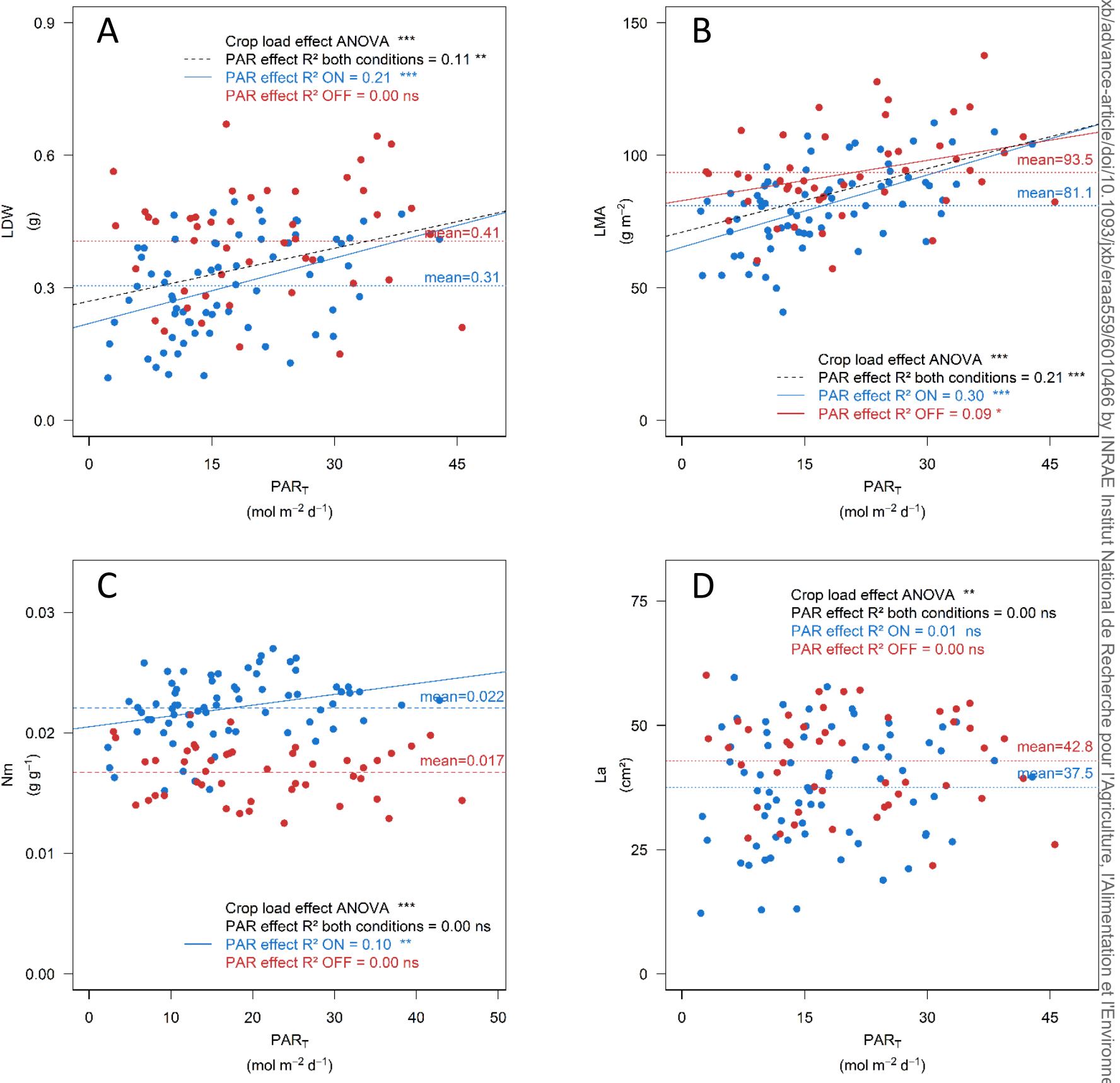

Fig. 6.

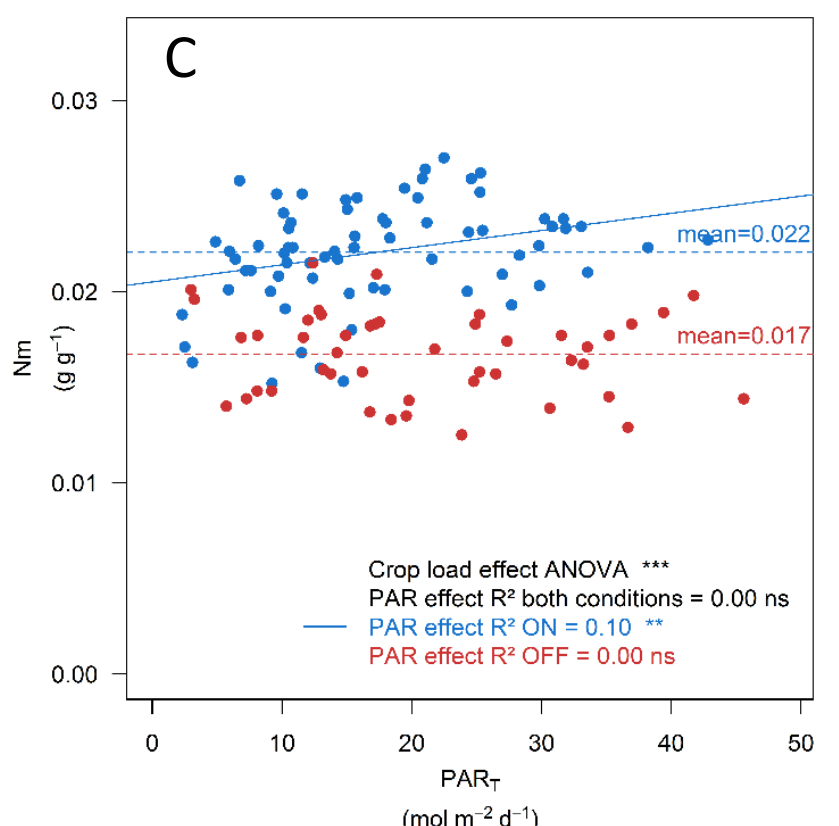

$\left(\mathrm{mol} \mathrm{m}^{-2} \mathrm{~d}^{-1}\right)$ 


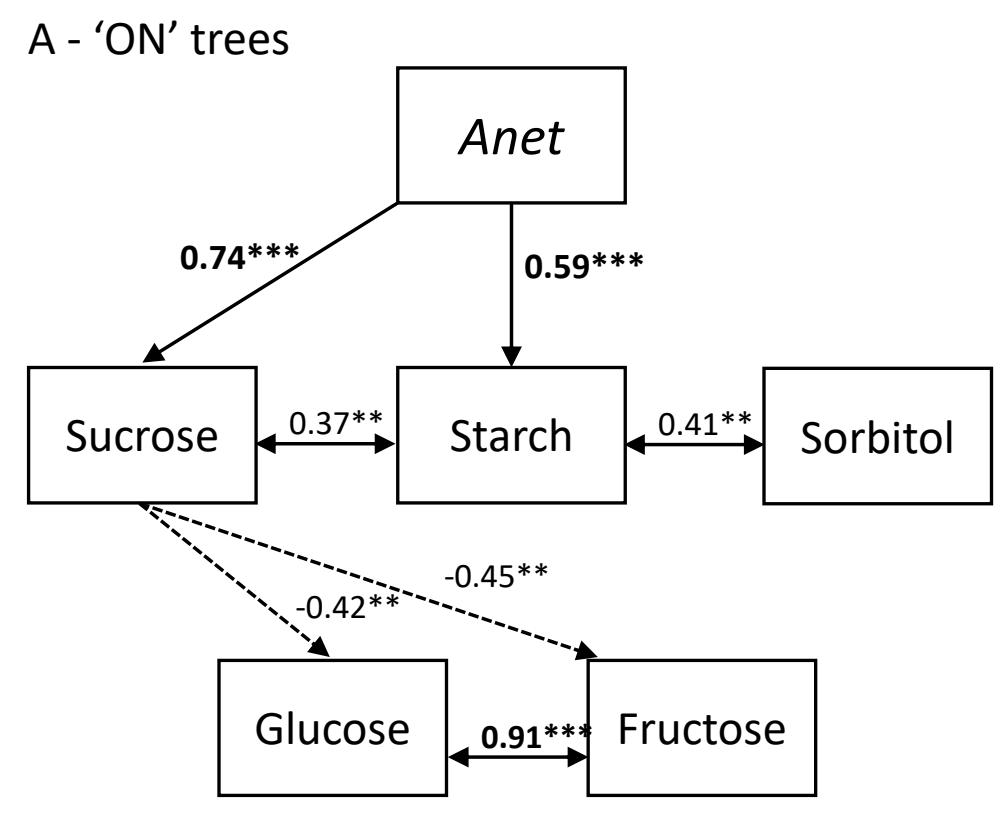

Fig. 7.

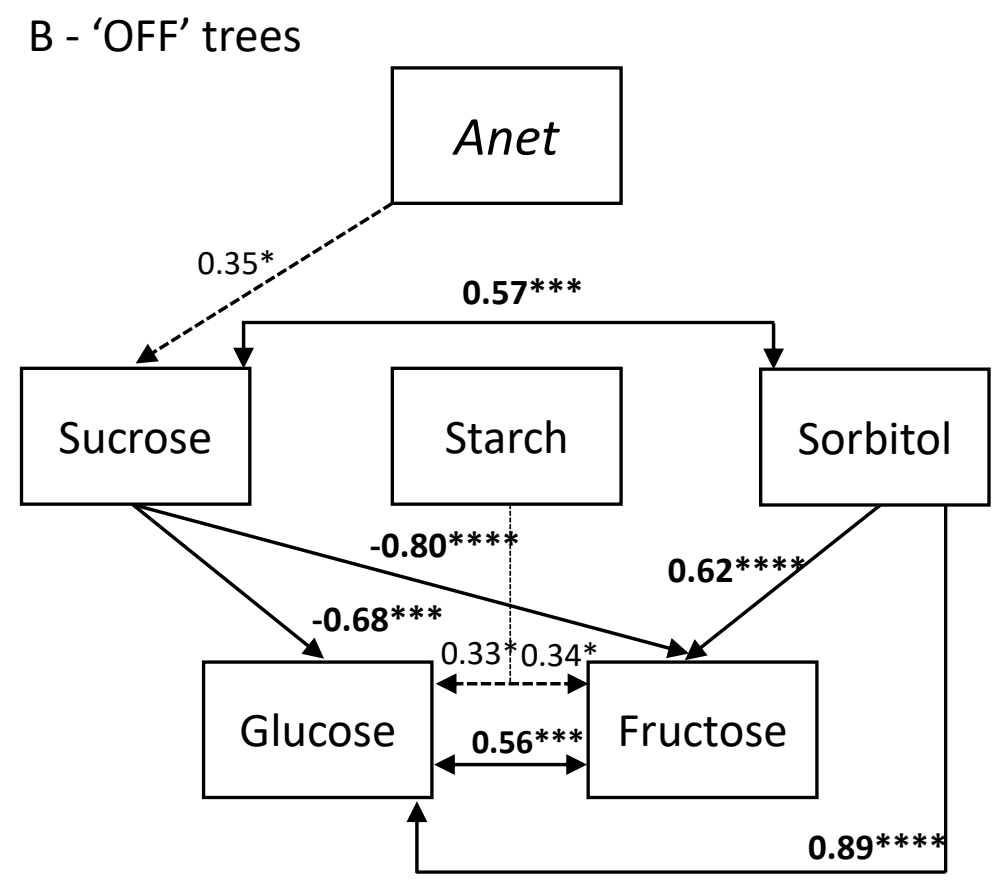

